\title{
DISTINTOS ENFOQUES SOBRE EL ESTUDIO DE LOS CRIMINALES MEXICANOS A FINALES DEL PORFIRIATO
}

Different Approaches to the Study of Mexican Criminals at the End of the Porfiriato

Yussel Arellano Navarrete ${ }^{1}$

Fecha de recepción: 4 de septiembre de 2019

Fecha de aceptación: 14 de enero 2020 


\section{Resumen}

El lema del Porfiriato, "orden y progreso", estableció la manera en la cual los hombres de bien junto con la ciencia permitirían que México lograse salir de un pasado conflictivo que lo mantenía en retroceso, en comparación con otras naciones. Ante un aumento considerable de delitos que afectaba la seguridad privada y el bienestar de la sociedad, algunos intelectuales de la época se dieron a la tarea de establecer las causas de la criminalidad en México, según sus particularidades biológicas y sociales. El presente artículo demuestra que los textos hechos por los criminólogos porfiristas van más allá de una connotación entre clase y raza, en la que solo se trasmitieron los fundamentos teóricos que discutían las escuelas de antropología criminal francesa e italiana, por medio de tres libros que fueron importantes para su tiempo, debido a sus consideraciones teóricas, metodológicas y aportaciones al conocimiento de la delincuencia mexicana

Palabras clave: Antropología criminal, Sociología Criminal, Delincuencia, Porfiriato.

\section{Abstract}

The Porfiriato motto, "Order and Progress", settled the way in which good men, along with science, would allow Mexico to leave behind a troubled past that kept it underdeveloped, in comparison with other nations. Due to a considerable increase of crimes affecting private security and society's welfare, some intellectuals set themselves to the task of knowing the causes of crime in Mexico, according to Mexicans biological and social characteristics. This article shows that Porfiristas criminology books go way beyond to a simple relation between social status and race, the theoretical foundations of French and Italian criminal anthropological schools - by three important books because of their theoretical and methodological considerations and contributions to the understanding of Mexican crime.

Keywords: Criminal anthropology, Criminal sociology, Delinquency, Porfiriato. 


\section{Introducción}

$\mathrm{E}$ 1 presente artículo expone las distintas perspectivas teóricas sobre el estudio del criminal implementadas por los primeros criminólogos mexicanos a finales del Porfiriato, por medio de tres publicaciones: la primera, escrita por los médicos Francisco Martínez y Manuel Vergara, Estudios de antropología criminal, publicada en 1892; la segunda, de la autoría del abogado Julio Guerrero, La génesis del crimen en México, escrita en 1901; la tercera, publicada en 1904 por el experiodista y funcionario de gobierno, Carlos Roumagnac, Los criminales en México. ${ }^{2}$

La historiografía sobre el crimen en México ha retomado como fuente primaria a los criminólogos del Porfiriato con variadas contribuciones. Robert M. Buffington (2001) analizó los discursos elitistas desde la perspectiva antropológica y la ley penal, a partir de lo cual concluyó que dichas ideas permitieron legitimar la práctica judicial para identificar y disciplinar a los transgresores. En el ámbito de la legislación penal, Elisa Speckman (2007) realizó un estudio sobre la administración de justicia en la Ciudad de México entre 1872 y 1910, cuyo objetivo fue comprender la distancia con respecto a las normas legales y la práctica judicial; además, la autora realizó un análisis detallado sobre los discursos en la criminalidad de la época porfirista. Por otro lado, Pablo Piccato publicó un estudio de la delincuencia a modo de sinónimo de "una historia de la ciudad y sus habitantes"(Piccato, 2010: 19). El autor centró su análisis en las distintas prácticas delictivas de hombres y mujeres, el cual fue el resultado de enfrentar una nueva forma de convivencia social, respaldada por la ley, establecida por los intelectuales porfiristas bajo la influencia positivista.

No obstante, se carece de textos académicos históricos que aborden los contenidos esenciales de los primeros estudios de los delincuentes mexicanos, los cuales se alejen de los preceptos europeos. Mauricio Schoijet (2009: 112) señala la necesidad de rescatar la historia de los orígenes de la cientificidad de las teorías que conformaron la criminología en México, ya que marcan un campo fértil en el área de la historia de las ideas y de las prácticas represivas. ${ }^{3}$ Buffington advierte que la historia de la criminalidad en América Latina debe ser analizada dentro de su contexto; por lo tanto, es necesario aproximarse a la noción propia de las reacciones al comportamiento criminal (Buffington, 2000: XI-XII).

Persiguiendo las ideas de Schoijet y Buffington las siguientes líneas pretenden demostrar que cada uno de los criminólogos que aquí analizaremos poseían objetivos distintos al escribir sobre los delincuentes. Las influencias teóricas europeas en los trabajos hechos por los intelectuales mexicanos, aunque son las mismas, la perspectiva y orientación de los análisis a los delincuentes difieren, lo que nos permite concluir que hay variables que deben considerarse y analizarse por separado. Lo anterior, incita a nuevas investigaciones, pues permitirán rescatar la esencia de las obras criminológicas de la época porfirista;

2- En el artículo solo se revisó el primer texto de criminología de Carlos Roumagnac, el cual contiene las causas de la delincuencia, sus influencias teóricas, una clasificación de delincuentes, algunas soluciones para combatir al crimen y las entrevistas y fotografías de los delincuentes. Roumagnac escribió dos obras sobre el mismo tema, Crímenes sexuales y pasionales (1906) y Matadores de mujeres (1910).

3- Schoijet presenta una revisión de los antecedentes de la antropología criminal en México, con ello rescata las distintas teorías y pseudociencias que sugiere como antecedentes de la antropología criminal, entre las que se encuentran: el degeneracionismo, la frenología, la antropología física, la craneología, el spencerianismo, el evolucionismo y la eugenesia. 
por ejemplo, de cómo el contexto social en relación con el científico provocó una mirada de los intelectuales a una clase marginada poco tomada en cuenta por las políticas gubernamentales; es, por tanto, una reflexión de lo que estorbaba para que una urbe se desarrollara exponencialmente, ya que la nación necesitaba una "sanación", la cual permitiría el progreso del país.

\section{Los delincuentes de la época porfirista}

El crecimiento industrial y económico que tuvo México en las últimas décadas del siglo XIX atrajo a cientos de nuevos habitantes, ya que los establecimientos comerciales demandaban ser atendidos, las fábricas solicitaban obreros para su funcionamiento; también se requirieron servicios domésticos en los hogares; sin embargo, la prosperidad que acontecía en el país trajo consigo un conjunto de problemas del cual la mayoría de las urbes de América y Europa padecían: el aumento de la delincuencia. Preocupados por este fenómeno social, los políticos, escritores e intelectuales se preguntaban cuál era el motivo. Algunos grupos conservadores lo relacionaron con la disminución de valores morales y religiosos (Gay, 1992: 16), otros lo vincularon con el consumo desmedido de alcohol, el abandono de la niñez y la falta de educación.

Los nuevos habitantes se establecieron en los márgenes de la Ciudad de México, barrios descuidados, lugares caracterizados por la falta de hábitos higiénicos y fuentes de enfermedades; relaciones personales desaprobadas por la sociedad moralista y conservadora porfirista, como los amasiatos; asimismo, los pobladores de estas zonas carecían de educación, lo que causaba la tendencia a la agresividad, según la tendencia regeneracionista; abusaban del consumo de alcohol en la vía pública, lo cual generaba constantes riñas y asesinatos. Por el contrario, las clases privilegiadas habitaban en las zonas céntricas, vestían elegantemente, asistían a colegios en los que recibían formación en ciencias, letras y artes; además eran dueños de los principales comercios, o bien, formaban parte del gobierno (Piccato, 2010: 46). Tal bipolaridad social, estaba respaldada por las teorías del degeneracionismo y la evolución de las especies; de tal modo que los factores de raza y clase determinaban el nivel de peligrosidad de las personas (Urías, 2000: 79).

Para combatir la delincuencia se llevaron a cabo mejoras en el cuerpo de la policía y se implementaron algunas restricciones en la venta de pulque. En 1903 se creó una nueva organización territorial para hacer eficiente la vigilancia de la policía; también, se hicieron propuestas para la profesionalización de sus elementos y el aumento de gendarmes en las calles, a pesar ello, el problema no disminuyó. A causa de la relación entre el consumo de alcohol y los delitos de sangre se implementaron algunas condiciones para su venta en la vía pública; no obstante, el control de la comercialización de estas bebidas fue difícil de implementar por el gran número de pulquerías que se establecían a lo largo de la ciudad (Piccato, 2010: 59).

El grupo de los científicos de la época porfirista adoptó al positivismo, una nueva ideología de origen europeo, ya que ofrecía una solución hacia los conflictos sociales que perturbaban el ideal modernizador del país; la cual consistió en proteger la economía, fundamentada en "racionalizar las desigualdades y reformular el concepto de libertad". En lo referente al derecho, los abogados mexicanos fueron

4- La ideología predominante en el siglo XIX fue el liberalismo; se fundamentó en el racionalismo de los humanos, sus derechos individuales y el respeto a sus libertades; entonces, aquel sujeto que corrompía la paz social: "rehúsa ser libre y por lo tanto es perverso", de esta forma, se justificaba su castigo (Olmo, 1999: 27-31). 
influenciados por la escuela positivista italiana, que en su afán de transformar la noción de delito y de cómo debía ser sancionado, encontró que por medio del método científico se podían establecer los orígenes del delincuente cambiando las viejas nociones del liberalismo que dotó al ser humano de libre albedrío (Speckman, 2006: 1421).

En lo referente a la delincuencia, surgieron en Europa teorías biologicistas, psicológicas y antropológicas, las cuales trataban de encontrar el origen del hombre criminal. Las más relevantes para la época fueron la antropología criminal italiana y la escuela antroposocial francesa, las cuales se fundamentaron en el evolucionismo de Herbert Spencer y el determinismo biológico de Charles Darwin, así que las conductas consideradas "anormales" estaban fundamentadas por la inadaptabilidad de algunas personas, ya que eran seres no evolucionados (Olmo, 1999: 27-31). Así fue como la delincuencia no solo se convirtió en un asunto de interés intelectual, sino que se consideró un obstáculo para las pretensiones del positivismo en el país, que bajo el lema "orden y progreso", los delincuentes, los desviados sexuales y los locos representaban un retroceso (Maya, 2015: 132).

En México, los interesados en resolver el problema de la delincuencia fueron médicos, abogados y un exinspector de policía, hombres sin formación específica en el tema, retomaron teorías construidas según la base científica positivista. ${ }^{5}$ Entre los representativos Francisco de Zayas, Francisco Martínez, Manuel Vergara, Porfirio Parra, Manuel S. Macedo, Julio Guerrero y Carlos Roumagnac. El objetivo de estos intelectuales fue encontrar todos los factores que contribuían a la criminalidad, de acuerdo con las características del contexto mexicano. ${ }^{6}$ La producción escrita que realizaron los criminólogos porfiristas, según Robert M. Buffington, fue una reiteración de prejuicios de raza, clase y género (2001: 98).

A continuación, se expondrán las tres obras que ya se mencionaron al inicio del texto, de las cuales rescataré los objetivos, las influencias teóricas, los factores que emplearon los autores para explicar las causas de la delincuencia, la metodología que emplearon y algunas medidas que los escritores pensaron podrían erradicar o contrarrestar el aumento de la criminalidad en la Ciudad de México.

\section{La antropología criminal de los médicos Manuel Vergara y Francisco Martínez}

En 1892 se publicó en México Estudios de antropología criminal, texto que registró las características físicas, ambientales y psicológicas de los criminales mexicanos. Los médicos Manuel Vergara y Francisco Martínez retomaron las teorías europeas de la antropología criminal italiana y la antroposocial francesa. El concepto del delincuente que adoptaron se fundamentó en que estos seres poseían características físicas visibles, las cuales eran determinadas por factores hereditarios, de tal manera que esos "estigmas" los convertía en un sector de la humanidad distinta a la de los hombres de "bien":

5- Se buscó la igualdad jurídica eliminando los tribunales especiales y los procedimientos penales pues debían estar sustentados en el cuerpo de leyes creadas por el Estado (Speckman, 2007: 47). En cuanto a la policía, esta debía cambiar sus estrategias, pasar de un vigilante de barrio a un instrumento del Estado (Piccato, 2010: 76).

6- El Código Penal de 1871 señalaba como transgresiones a la ley las siguientes: delitos contra la propiedad; delitos contra las personas, la falsedad, la revelación de secretos, delitos contra las buenas costumbres, delitos contra la salud pública, delitos contra el orden público, delitos contra la seguridad pública, atentados contra las garantías constitucionales (Código Penal, 1871). 
como una familia en la especie humana, y que se diferencia de los demás hombres, por ciertas anomalías de conformación facialmente reconocibles; que es de todo punto falsa la aserción de que el libre albedrío sea el fundamento de la responsabilidad criminal, y que, lejos de esto, el crimen no es más que el resultado de una anomalía cerebral, congénita o adquirida, que arrastra e impulsa fatalmente al hombre a obrar en un sentido determinado (Martínez y Vergara, 1892: 178).

El texto de los médicos, Francisco Martínez y Manuel Vergara, dialogó con las teorías que hasta ese momento debatían el origen del crimen, entre las más importantes se encuentran las posturas determinantes y los predisponentes biológicos en el hombre de Alexander Lacassagne, la correlación entre las enfermedades del cerebro con la delincuencia de Mortiz Benedikt y la teoría del criminal nato de Cesar Lombroso.

Uno de los principales motivos para realizar un estudio sobre los delincuentes mexicanos fue sentar nuevas bases en el derecho penal mexicano para distanciarse de los principios fundamentales, que se caracterizaban en ese momento por ser dogmáticos, allegados a una "psicología metafísica" (Martínez y Vergara, 1892: III). Los médicos buscaban pruebas visibles en los criminales que fueran comprobables en los juicios de defensa o de responsabilidad criminal de los trasgresores de la ley, ya que, en muchas ocasiones, se dejaba en libertad a personas peligrosas para la sociedad y se culpabilizaba a inocentes.

El trabajo de estos médicos se basó en el análisis de veintiséis hombres y mujeres prisioneros en la cárcel de Puebla. La metodología que utilizaron consistió en realizar una ficha técnica del delincuente, la cual contenía tres fotografías del reo (frente, perfil izquierdo y derecho), un resumen de su delito; asimismo, se observaba si el delincuente poseía alguna anormalidad física. Posteriormente, en otra foja, se incluía un cuestionario que reunía los datos generales del criminal, estos eran: nombre, edad, oficio, raza, religión, lugar de origen, lugar de vecindad y domicilio de la última residencia antes de cometer la trasgresión.

Otro aspecto significativo que consideraron los médicos Martínez y Vergara fue la reconstrucción de la biografía del reo, consistió en registrar los antecedentes de padres y familiares cercanos, costumbres, datos patológicos, y el estado mental tanto del reo como de sus familiares. También, creyeron importante el registro de los datos antropométricos de los delincuentes, como la estatura, el peso, la apertura braquial, la amplitud torácica, las asimetrías y las anormalidades observables; la fisonomía; y la organoscopía, la cual consistió en una serie de pruebas que daban cuenta de la sensibilidad al dolor, al calor, al frío; el nivel de fuerza; los reflejos y la percepción de los sentidos.

Por último, realizaron un estudio psicológico de los criminales, el cual fue asentado según la percepción de los médicos. La valoración psicológica radicó en la inspección del desarrollo de la inteligencia, el estado mental, además del nivel de imaginación. Otro elemento que tomaron en cuenta fueron los sentimientos, las afecciones y las pasiones; así como el valor civil. Resulta interesante que los médicos registraron el lenguaje de los interrogados durante la entrevista; también el nivel de educación, los tipos de tatuajes en forma y tamaño, la manera de escribir e incluso si hacían uso de jeroglíficos.

Uno de los aspectos más llamativos de Estudios de antropología criminal fue determinar las características fisonómicas y antropométricas de los delincuentes mexicanos, labor que se fundamentó en la idea de la anormalidad de los criminales. Lo anterior cumplía con un doble propósito: comprobar sí las 
teorías europeas coincidían o no con la realidad nacional y establecer por primera ocasión una clasificación de los criminales mexicanos según sus rasgos físicos.

La investigación señaló algunas diferencias entre los delincuentes mexicanos y los europeos; por ejemplo, de acuerdo con los antropólogos europeos, los climas fríos se relacionaban con los robos; los cálidos con los delitos contra las personas. Vergara y Martínez especificaron que en el país no existía tal relación, puesto "que los indios son ladrones cualquiera que sea el clima o el lugar que habiten" (Martínez y Vergara, 1892: 2), agregaron que, en lugares fríos, como en un pueblo del centro de México, "San Pablo, todos son asesinos feroces, y por excepción son ladrones" (Martínez y Vergara, 1892: 3). Estas ideas estaban fuertemente relacionadas con las teorías degeneracionistas del siglo XIX.

Al comparar las características físicas de los delincuentes mexicanos con las de los criminales europeos, los investigadores mexicanos encontraron algunas diferencias, por ejemplo, no consideraron a la calvicie como un elemento que indicase anomalía del maleante, debido a que es un rasgo de la raza blanca. En el caso de México, la mayoría de los delincuentes fueron hombres indígenas, quienes presentaban cabello abundante y oscuro, por el contrario, el del criminal europeo era claro y escaso. Algunas similitudes fueron la nariz torcida o asimétrica y las orejas en asa (Martínez y Vergara, 1892: 99).

La clasificación fisonómica de acuerdo con el tipo de delitos quedó establecida de la siguiente manera: homicidas y acusados por lesiones poseían mirada fría y vidriosa, pómulos anchos y salientes; nariz aguileña, barba abundante, labios delgados. Los ladrones presentaban una mirada penetrante, pero esquiva cuando se les hablaba; nariz roma y levantada; labios plegados. Los violadores ostentaban ojos grandes y salientes, mirada clara y brillante, labios gruesos y "volteados", lampiños, los médicos enfatizaron que eran propensos a abusar de sus familiares más cercanos (Martínez y Vergara, 1892: 100).

El estudio realizado por estos médicos clasificó a los delincuentes mexicanos a partir de características propias determinadas por la raza, la geografía de lugar de origen e historial de enfermedades de sus familiares; sin embargo, este análisis relacionó a los indígenas con la delincuencia, legitimando el discurso y la percepción que las clases altas y letradas tenían sobre la misma. El texto no ofrece soluciones para combatir a la delincuencia, ya que el motivo de su elaboración fue demostrar que el concepto del libre albedrío no era del todo cierto según las nociones del derecho penal clásico.

La investigación antropológica de los médicos poblanos fue recibida con entusiasmo, contribuyó en la introducción del método Bertillon en el Código Penal de Procedimientos Penales de 1894, el cual estableció el retratar y medir a los delincuentes tras dictarse el auto de formal prisión (Speckman, 2001: 205). La comunidad científica de México reconoció el rigor científico de la obra, ya que el método que emplearon se apegó a lo establecido por las teorías de la antropología criminal italiana; de tal modo que abrió la discusión e interés entre algunos especialistas y aficionados de la conducta criminal.

La propia evolución de la ciencia criminológica fue incorporando y desechando elementos que ayudarían a comprender el origen de la delincuencia; de tal manera, el clima, la geografía y hasta la alimentación fueron considerados para dicho fin. Un ejemplo de lo anterior en México, lo representa el estudio elaborado por Julio Guerrero, quien en 1901 examinó factores que determinaban la psiquis del mexicano, para ello consideró la historia de México, el clima, el territorio y la religión. 


\section{La sociología criminal de Julio Guerrero}

Julio Guerrero presentó en 1901 Génesis del crimen en México, texto de análisis de psiquiatría social en el que incluyó una profunda reflexión sobre las causas que generaban el crimen en México. Para Guerrero, la delincuencia era un "fenómeno complejo, como todos los sociales" (Guerrero, 1901: IX); además, era una manifestación individual de un fenómeno general, ya que afectaba a otros individuos.

De acuerdo con Guerrero, el crimen es un conflicto generado por aquellos que habían abandonado aspiraciones generales, estos seres carecían de sentimientos e ideas, y que concebían la vida como una lucha abierta, a modo "de un episodio de la evolución animal". Los factores que Guerrero englobó en su estudio sobre la delincuencia en México conforman un conjunto dado por la naturaleza, que afecta de manera psíquica y social a los individuos, además de constituirse en "un factor destructor del espíritu humano" (Guerrero, 1901: VII-VIII).

El objetivo de este autor fue investigar las causas que determinaban la producción de los crímenes en el centro y meseta de México; para lograr dicho propósito, se propuso identificar las perversiones del carácter, el nivel de inteligencia, los males de la sociedad: “Mi estudio es de Psiquiatría, de vicios, de errores, preocupaciones, deficiencias y crímenes. No hará mención de virtudes o de triunfos, solo en algunas ocasiones que haga falta desmentir algún prejuicio" (Guerrero, 1901: XII). El autor consideró todos los factores que influían en las personas y de allí notar su afectación para lo que debía indagarse en la generalidad, después determinar qué aspectos generaban "los vicios al pensar, obrar y sentir" (Guerrero, 1901: XII).

Resulta interesante la categorización de los delincuentes según su estrato económico y sexo hecha por Julio Guerrero ${ }^{7}$ cada grupo socioeconómico comparte un conjunto de características culturales, laborales y de comportamiento; por ejemplo, se consideraba que los del rubro más bajo fuesen sucios, analfabetas, y alcohólicos, promiscuos, proclives a las lesiones y robos; por el contrario, las más elevadas se caracterizaban por vestir elegantemente, formados en los mejores centros de educación, limpios, respetuosos, monógamos, no se les relaciona con conductas criminales (Guerrero, 1901: 160-182). En el caso de las mujeres, aquella que se apartaba del estereotipo establecido en el porfiriato, era considerada como "criminal en potencia", susceptible a delitos de índole moral como el infanticidio, la prostitución, el adulterio y la corrupción de menores (Speckman, 1997: 201).

El texto de Guerrero se divide en secciones a las que se refiere como libros. El primero, "La atmósfera", analizó las características del medio ambiente del centro de México, el cual forjaba el carácter perezoso de los mexicanos, Guerrero señaló que, al incrementarse la temperatura, el tipo de aire cambiaba, causando el apaciguamiento de las actividades laborales; para sobrellevarlo las personas acostumbraban largas conversaciones y consumían exageradas cantidades de café, tabaco o alcohol. La creencia de

7- Esta categorización se divide en Hombres y mujeres infelices que no tienen medio para vivir, se caracterizan por ser sucios, alcohólicos, promiscuos; recurren en delitos como lesiones, riñas y robos. Hombres y mujeres jerarquizados entre sí, según el monto de su salario, pero con un mismo coeficiente de moral, hábitat y costumbres, por lo general eran artilleros, soldaderas, trabajadores industriales, sirvientes, se caracterizaban por conductas delictivas como riñas, lesiones, adulterio, aborto, infanticidio, abandono infantil, robo. Hombres y mujeres que forman un hogar definitivo, aunque no insoluble, afrontan toda la responsabilidad para formación y mantenimiento de una familia; conformado por artesanos y pequeños comerciantes, con un mayor grado de educación que los sectores anteriores, los hombres son pocas veces alcohólicos y las mujeres son pudorosas, no tienen más delitos que algunos pleitos de vecindad e injurias. Por último, los trabajadores con solvencia económica acomodada y los intelectuales, que no están relacionados con delitos, solo con inestabilidades mentales en las mujeres, como la histeria (Guerrero, 1901: 160-182). 
la mayoría de los mexicanos en la magia y el ser fervientes católicos podía entenderse por el clima impetuoso, pues eran frecuentes las inundaciones y sequías, lo que generaba la ruina de los cultivos, creando en la "psiquis" de los afectados un desánimo que prevalecía de generación en generación, pues no existían garantías de obtener un porvenir, de allí que se aferraran a los milagros o a fuerzas ajenas que prometían protección a su porvenir (Guerrero, 1901: 11-33).

La segunda sección, "El territorio", enfatizaba que desde la época del Virreinato la capital de México fue la misma, en la cual se concentró la civilización; de acuerdo con el autor, el aislamiento de las ciudades, las villas y los pueblos tuvo como consecuencia la falta de solidaridad nacional, la ausencia de confianza en el gobierno y la anarquía de los gobiernos locales. Lo anterior, explicaba el lazo íntimo generado entre familias que conocemos como "compadrazgo", en ese contexto, las personas necesitaban de la lealtad absoluta de los miembros cercanos a la familia (Guerrero, 1901: 80-84). En este mismo apartado, Guerrero reflexiona sobre el carácter celoso de los mexicanos, lo adjudicó a una cuestión de herencia dada por los españoles; ya que, para el hombre, la esposa es compañera de vida, la amiga a la que se le confiesan los anhelos, de ahí la gravedad del adulterio por parte de la mujer, pues además del engaño sentimental, significaba que se abrió la puerta a los enemigos (Guerrero, 1901: 120-126).

En la tercera parte, "El citadismo", argumenta sobre la pereza mexicana, siendo esta de origen social y no climática. El autor se fundamentó en la mala alimentación de los trabajadores, causada por un territorio infértil o con características climáticas que no favorecían las cosechas que con tanto tiempo habían preparado. La demora o la lentitud en el trabajo de los mexicanos se debía al "miedo" de que al día siguiente no se tendría más, ya que no había demasiadas oportunidades laborales. Otro aspecto que consideró de suma importancia fue el alcoholismo de los habitantes de México, sea cual fuese su estrato económico; pues el uso de las bebidas embriagantes se encontraba arraigado en la cultura del país: los obreros y los campesinos bebían a causa de los infortunios de la vida, mientras que para las clases sociales acomodadas el alcohol era parte de todo evento social, trátese de una fiesta de cumpleaños, negocios o logros académicos.

La cuarta parte, "Los atavismos", retomó un factor hereditario que explicaba el carácter bélico de los mexicanos, el cual procedía de nuestro pasado prehispánico, en el que las ceremonias religiosas se caracterizaban por ser sanguinarias y crueles. Ese remoto elemento había permanecido latente por muchas décadas, pero se reactivó durante las distintas guerras que surgieron a partir de 1810 "con el grito de Independencia" hasta 1873. En consecuencia, esos conflictos trajeron destrucción e inseguridad en todo el territorio mexicano; por ejemplo, en lo económico se generó un endeudamiento enorme de la nación, además del abandono de pueblos y villas a causa de saqueos por parte de "los pronunciados" (Guerrero, 1901: 228). Las constantes guerras produjeron "el aniquilamiento biológico", los hombres se hicieron más pequeños; los animales de carga, los caballos y burros, débiles; el ganado vacuno y porcino "menos corpulento"; lo mismo ocurrió, con los vegetales y frutos (Guerrero, 1901: 243-247).

En la última parte, "Los credos", realizó un análisis del papel de la iglesia católica en la nación mexicana. Guerrero mencionó el desprestigio de la institución religiosa por haber desprestigiado sus enseñanzas morales y quebrantado la gran autoridad que tenía sobre la masa de analfabetos, que, según el autor, siempre era la mayoría de cualquier pueblo. Guerrero consideró a la iglesia como un factor que frenaba el desarrollo del país, dado que muchos de sus seguidores (mujeres, analfabetas, campesinos) se regían por el ayuno, la predicación de la pobreza y el rechazo a la modernidad. El autor pensaba que la religión 
debía impulsar entre sus partidarios la creación de una sociedad moderna, inspirarla al trabajo, motivarla al abandono de la idea de la precariedad; además, practicar "la serenidad del espíritu, la profundidad de las meditaciones, el vigor del brazo y la constancia de la voluntad" (Guerrero, 1901: 297). La crítica de Guerrero hacia la iglesia católica de México era compartida por los intelectuales de la época debido a la influencia del positivismo e ideas cientificistas que se discutían en las distintas academias y comunidades de letrados del país.

En el mismo apartado, Guerrero señaló que la desmoralización de la juventud mexicana tenía efectos negativos en la sociedad, se quejó de la actitud del gobierno, puesto que al sustituir la enseñanza religiosa en las escuelas por una laica, había provocado el vacío "armónico del espíritu"; de tal modo que la Instrucción Pública era responsable de un desorden de pensamientos, de comportamientos sexuales tempranos que solo traían más dificultades, como el abandono de los estudios por parte de los jóvenes, matrimonios conflictivos, además de generar hombres y mujeres improductivos para la nación (Guerrero, 1901: 322).

Génesis del crimen en México señaló los factores que tenían influencia en el carácter de los mexicanos. Para Guerrero la violencia que existía en algunos pueblos, así como los delitos contra las personas se explicaban por cuestiones de una herencia arraigada en nuestra psiquis debido a un pasado bélico. La degeneración de la población se debía a un medio ambiente hostil. Aunque Guerrero no propone soluciones para resolver los factores anteriores, remarca la necesidad de una sociedad educada y alimentada correctamente.

Las dos anteriores obras criminológicas abarcan las causas generales de la delincuencia y de cómo los factores biológicos, climatológicos y sociales pueden afectar la conducta humana en el contexto mexicano. Para 1904, Carlos Roumagnac realizó un análisis de los delincuentes diferente a sus antecesores, pues uno de sus objetivos fue el estudio individualizado de los criminales, apartándose de la generalidad de las causas del crimen.

\section{La psicología criminal, observaciones de Carlos Roumagnac}

El último de los criminólogos porfiristas fue Carlos Roumagnac, periodista crítico al régimen político mexicano, encarcelado en cuatro ocasiones: tres por denuncias sobre corrupción de miembros cercanos a Porfirio Díaz y una por apología del delito; sin embargo, a inicios del siglo XX buscó servir al bien de la nación desde otra posición, ya no como opositor al gobierno sino como parte de este. En 1900 fue por poco tiempo jefe de policía de la Ciudad de México en la que impulsó la creación de una gendarmería científica. Posteriormente, ocupó un cargo administrativo en una sección del ministerio de gobierno permitiéndole el acceso a las prisiones de la Ciudad de México. ${ }^{8}$

8- Carlos Roumagnac impulsó la creación de una policía científica durante su cargo de jefe de policía. Una de sus primeras acciones fue la publicación de un extracto traducido de la obra de Hans Gross, Manual del Juez como Sistema de Criminalística; el cual pretendía instruir a los jueces, miembros de la policía y jefes de demarcación en el quehacer de su investigación En 1908 Roumagnac dictó cinco conferencias dirigidas a todo el cuerpo policial y al público general, en ellas mencionó la función de los jueces e inspectores de policía, de igual manera, los métodos existentes para la identificación de criminales y el análisis de la escena del crimen como técnicas que todo policía debía tener; sin embargo estas acciones no tuvieron mayor trascendencia en la práctica de la policía ni en el establecimiento de una escuela de policía, pues fue hasta 1923 con la creación de la Escuela Técnica de Policía en la Ciudad de México, de la cual Roumagnac fue profesor (Arellano, 2018: 47). 
Escribió su primer texto sobre los criminales en México alrededor de 1904 con el propósito de generar interés entre los especialistas del tema, pues según Roumagnac no existían suficientes trabajos sobre los delincuentes en comparación con otros países; además, se había priorizado en la morbosidad del acto criminal dando impulso al periodismo amarillista. Igualmente se propuso derrumbar prejuicios de clase y raza, ya que no solo los sectores bajos de la sociedad cometían delitos sino también los hombres "honrados", quienes evadían un castigo judicial bajo el argumento de un crimen pasional.

Para Roumagnac, lo que importaba era conocer las causas individuales que propiciaban la delincuencia; una vez obtenidas, el gobierno debía ser capaz de crear instituciones que ayudarían a erradicarla, identificando a los delincuentes que pudieran ser rehabilitados; por el contrario, los que no fueran susceptibles de ello debían ser confinados a la prisión, o bien, en campos de trabajo, a fin de que no volviesen a las calles, pues no serían capaces de abstenerse a un acto delictivo. Finalmente, planteó su interés en que el estudio del hombre criminal tenía que hacerse en sus causas individuales, de esta manera se evitaría la reincidencia de los delitos.

Con el propósito de conocer al hombre delincuente en su individualidad, Roumagnac hizo uso de la entrevista, recurso que retomó de los doctores franceses Emile Laurent y Henry Maudsley, y el estadounidense Arthur McDonald. Roumagnac profesó como ellos que la entrevista era el método idóneo para comprender las conductas criminales; por lo tanto, se debía retratar los datos biográficos del reo de la forma más fiel posible y así presentar "documentos humanos" (Roumagnac, 1904: 12).

El uso de la metodología de la entrevista tenía como principal objetivo identificar los componentes que causaron el daño, particularmente a través del estudio de la niñez y de la adolescencia, etapas del individuo que en la adultez reflejaban las "normas de conducta aprendidas" (Ramírez, Bergalli, y Millares, 1983: 78). Si el medio en que la persona se desarrolló no se encontraba dentro de lo aceptable, según los cánones sociales, se podrían generar factores que desembocaran en un comportamiento antisocial.

Roumagnac consideró de suma importancia conocer los aspectos familiares y de educación del criminal debido a que la familia y la escuela son las primeras instituciones que rigen la vida del hombre, las cuales proporcionarían elementos en el historial psicológico, lo que permitiría rastrear ciertas conductas que finalmente habían desembocado en una trasgresión. Para ello entrevistó a 49 reclusos: cinco menores de edad, 16 mujeres y 25 hombres de las cárceles de Belén y de La Penitenciaria.

De acuerdo con la información obtenida de las entrevistas, Roumagnac concluyó que existían causas sociales y predisponentes que provocaban que las personas cometieran delitos. Las de origen social eran principalmente originadas por el abandono de la niñez, el pauperismo, la mendicidad y la embriaguez; las predisponentes, intrínsecas al individuo se referían a la raza, el temperamento, la edad, el sexo, el clima, entre otros; sin embrago, el autor concluyó que los condicionados por lo social tenían más peso que los de la casta o la herencia familiar.

Uno de los grandes males que afectaba al país era el alcohol, Roumagnac, Guerrero y Martínez y Vaca, al igual que la mayoría de sus contemporáneos, pensaban que era el principal generador de miseria y de delitos. Nicolás Ramírez de Arellano, médico porfirista, presentó un texto sobre los efectos de las bebidas embriagantes en la conducta humana, la cual consideró una enfermedad (Ramírez, 1895). Trinidad Sánchez Santos enfatizaba que el alcohol afectaba al ser humano en tres niveles: el individual, la descendencia y generaba conflictos sociales (Sánchez, 1896). El énfasis de Roumagnac por señalar al alcohol como el origen de todo mal de la sociedad mexicana estuvo influido por su cargo en la policía, pues en la 
práctica se percató de que durante los días de fiesta se consumían más bebidas etílicas, consecuentemente todos los delitos aumentaban; por el contrario, cuando existía una restricción de la ley para su venta, las infracciones disminuían.

Por lo anterior, consideró al alcoholismo como una de "las grandes causas engendradoras de la delincuencia en México", ya que "es un factor que se aprende y degenera la mente al mismo tiempo" (Roumagnac, 1904: 59), ya que afectaba las funciones del cerebro, las deterioraba según el tiempo en que el individuo lo hubiese consumido; en consecuencia, sus descendientes heredan un funcionamiento nervioso afectado, además de que los padres ebrios daban mala vida y pésimo ejemplo a sus hijos. Roumagnac propuso erradicar ese mal social por medio de un impuesto "casi imposible de pagar". Los consumidores de esta bebida embriagante eran "el bajo pueblo", al ser de bajo costo y de fácil acceso, al incrementar el precio los consumidores desistirían de su uso (Roumagnac, 1904: 48).

La solución ante la criminalidad que Roumagnac propuso fue erradicar sus orígenes, es decir, al alcoholismo y la falta de educación, al abandono físico y moral de los infantes. El alcoholismo debía ser erradicado con altos impuestos; la falta de educación con la apertura de centros de enseñanza para personas de bajos recursos; el abandono físico y moral de los menores de edad se tenía que apartar a los padres problemáticos de los hijos, llevándolos a lugares de acogida en los que se les instruiría en moral y educación, pues aún estaban a tiempo para reformarse.

El texto de Los criminales en México fue uno de los primeros en registrar la corrupción y prácticas cotidianas que acontecían en las cárceles de Belén y en La Penitenciaría en el Porfiriato. Las entrevistas que el autor realizó a los reclusos y reclusas mencionan el uso de drogas (principalmente marihuana), abusos sexuales, homosexualismo; además de malos tratos por parte de las autoridades hacia los prisioneros; sin embargo, el autor no realiza mayor observación o denuncia; no obstante, mencionó la necesidad de reformar el sistema penitenciario, pues lejos de ser un entorno para reformar a los delincuentes eran lugares en los que se generaban nuevos vicios y degeneración moral.

La obra de Roumagnac es un acercamiento individual a los delincuentes de aquella época, lo cual resulta interesante, pues su metodología y práctica configura a un antecedente de la psicología criminal o criminología clínica en México. Las entrevistas a los delincuentes proveen al investigador de nuestro presente material valioso para analizar cuestiones sociales y culturales, asimismo para la historia de las prisiones en México.

\section{Conclusión}

Las consideraciones teóricas de los criminólogos mexicanos son variadas, no se apegan a una corriente en particular, incluyen referencias de pensadores europeos, lo que no debe considerarse una falta de análisis o de cientificismo por parte de los autores, ya que se debe tener en cuenta que la ciencia criminológica se encontraba en constante transformación; se incluían o excluían factores que determinaban a un criminal, fuesen biológicos, fisiológicos, psicológicos, psiquiátricos, sociales, etcétera.

9- No es extraño encontrar en los textos de criminología de la época la constante comparación entre los hombres "honrados" y los del "bajo pueblo" (Speckman, 2007: 63; Garza, 2012: 7). 
El análisis de estas tres obras muestra que cada una de ellas fijó distintos objetivos, pero la finalidad era la misma, encontrar las particularidades de la delincuencia mexicana dentro de su contexto, no existe una transcripción de las teorías europeas sino una adaptación de estas. Por ejemplo, Roumagnac reconoció la categoría del "criminal nato" pero no la consideró determinante para la delincuencia, mostró cautela al describir físicamente a los delincuentes entrevistados, ya que consideró tales observaciones como "caracteres criminalizados" (Roumagnac, 1904: 13), postura que retomó de la escuela criminal de antropología francesa. Los médicos poblanos si bien realizaron un estudio antropológico y antropométrico de reos, fijaron las características de los delincuentes mexicanos, los cuales no eran similares a los europeos. Guerrero, por su parte, hizo un recuento de los males del mexicano, el cual no resulta ser más que negativo, ya que todos los factores que analizó son de orden cultural, biológico e histórico.

Los criminólogos del Porfiriato que aquí mostramos son resultado de una reacción ante los altos índices de criminalidad que se registraba a finales del siglo XIX e inicios del XX. Al ser miembros allegados al poder y tener influencias ideológicas dadas por el positivismo y el desarrollo propio de las ciencias contribuyeron con investigaciones que pretendían conocer a los delincuentes mexicanos. Otro factor importante que buscaron reformar fue en el campo del derecho penal para asignar la responsabilidad criminal en los casos de aparente ebriedad o bajo un episodio de locura; es decir, fue una época de cambios ideológicos en la cual los intelectuales buscaban legitimar o bien, realizar cambios en la estructura política.

Para concluir, los textos de criminalidad aquí presentados si bien reproducen un discurso de rechazo hacia los sectores marginados de la sociedad; también indican los males que aquejaban al país, así como las primeras propuestas para su solución, aunque no son demasiadas, pues el Estado se enfrentaba a un nuevo elemento, me refiero a la delincuencia en las urbes. Son entonces una fuente invaluable en las que se refleja la cultura, el desarrollo de la ciencia y la percepción de distintos sectores sociales por parte de la elite del porfiriato.

\section{Referencias}

Arellano-Navarrete, Yussel. 2018. Carlos Roumagnac. Una biografia intelectual. Universidad Autonóma del Estado de México.

Buffington, Robert. 2000. Introduction: Conceptualizing Criminality in Latin America. En Reconstructing Criminality in Latin America, editado por Carlos Aguirre y Robert Buffington. Wilmington, Del : Scholarly Resources, 11-19.

. 2001. Criminales y ciudadanos en el Mexico moderno. México: Siglo XXI.

Código Penal para el Distito Federal y Territorios de Baja California sobre delitos del fueron común y para toda la República sobre delitos contra la Federación. 1871. Veracruz, México: Imprenta del PROGRESO de Ramón Lainé.

Garza -James, Alex. 2012. El lado oscuro del Porfiriato. Sexo, crímines y vicios en la ciudad de México. México, México: Aguilar.

Gay, Peter. 1992. La experiencia burguesa de Victoria a Freud. La educación de los sentidos. Méxcio, México: Fondo de Cultura Económica. 
Guerrero, Julio. 1901. La génesis del crimen en México. Estudios de psiquiatría social. México, México: Imprenta de la Vda. de Ch. Bouret.

Martínez-Baca, Francisco y Manuel Vergara. 1892. Estudios de antropología criminal. México, México: Imprenta y litografía de Benjamin Lara.

Maya-González, José. 2015. Locura y criminalidad en el discurso médico porfiriano: el caso de Enrique Rode, 1888-1891. Trashumante. Revista Americana de Historia Social, (5): 128-149.

Olmo, Rosa del. 1999. América Latina y su criminología. México, México: Siglo XXI.

Piccato, Pablo. 2010. Ciudad de sospechosos. Crimen en la Ciudad de México 1900-1931. México, México: México: Centro de Investigaciones y Estudios Superiores en Antropología Social/Fondo Nacional para la Cultura y las Artes, (Publicaciones de la Casa Chata).

Ramírez-Bustos, Juan; Roberto Bergalli y Teresa Millares. 1983. El pensamiento criminológico. Un análisis crítico. Colombia: Temis.

Ramírez de Arellano, Nicolás. 1895. El alcoholismo en México. En Primer Concurso Científico Mexicano. México: Oficina Tipográfica de la Secretaría de Fomento.

Sánchez-Santos, Trinidad. 1896. El alcoholismo en la república mexicana. México, México: Imprenta del Sagrado Corazón de Jesús.

Schoijet, Mauricio. 2009. Algunos antecedentes de la antropología criminal de Césare Lombroso. Alegatos, (72): 111-126.

Speckman, Elisa. 1997. Las flores del mal. Mujeres criminales en el porfiriato. Historia Mexicana, 47 (1): 183-229.

. 2001. El derecho penal en el porfiriato: un acercamiento a la legislación, los dis-

cursos y las practicas. En En Proyectos legislativos y otros temas penales. Segundas Jornadas sobre Justicia Pena, editado por Leticia A. García Ramírez,Sergio \& Vargas Casillas. México: UNAM, 201-212.

. 2006. Los jueces, el honor y la muerte. Un análisis de la justicia (ciudad de México, 1871-1931). Historia Mexicana, 55 (4): 1411-1466.

2007. Crimen y castigo. Legislación penal, interpretaciones de la criminalidad y administración de justicia (Ciudad de México. 1872-1910). México, México: El Colegio de México-Universidad Nacional Autónoma de México.

Urías-Horcasitas, Beatriz. 2000. Indígena y criminal: interpretaciones del derecho y la antropología en México, 1871-1921. México, México: Universidad Iberoamericana. 